\title{
Acute liver failure due to visceral leishmaniasis in Barcelona: a case report
}

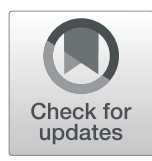

Iratxe Martinez de Narvajass ${ }^{1,2}$, Alba Díaz $3^{3}$, Octavio Bassegoda ${ }^{4}$, Adriá Carpio ${ }^{4}$, Carla Fuster ${ }^{3}$, María Eugenia Valls ${ }^{5}$, Miriam J. Alvarez-Martínez ${ }^{5}$, Carolina García-Vidal², Alejandro Soriano², José Antonio Martínez² and Juan Ambrosioni ${ }^{2^{*}}$

\begin{abstract}
Background: Leishmaniasis is an emerging infectious disease. Due to human migration and tourism, visceral leishmaniasis may become more common in non-endemic areas. In the Mediterranean basin, visceral leishmaniasis typically occurs in rural regions.

Case presentation: We present an unusual urban case of acute liver failure due to visceral leishmaniasis, following a prolonged fever of unknown origin. After obtaining negative results from the bone marrow aspirate, we performed a liver biopsy that elucidated the diagnosis. The liver involvement in visceral leishmaniasis may appear as chronic granulomatous hepatitis. However diffuse hepatitis process, a necro-inflammatory pattern, without forming granulomas were observed in the liver biopsy specimens in this case. Intracytoplasmic Leishmania amastigotes were observed in the liver biopsy specimens and a polymerase chain reaction confirmed the diagnosis. Only five pathological confirmed cases of acute hepatitis due to visceral leishmaniasis have been described so far, just two in adults and both from Barcelona. A revision of the literature is performed.

Conclusions: Acute hepatitis is an uncommon debut of visceral leishmaniasis in immunocompetent patients. Furthermore there are only few cases in the literature that describe the histopathological changes that we found in this patient. In conclusion, in case of acute hepatitis leading to liver failure, leishmaniasis should be considered a differential diagnosis (even in non-endemic countries and without clear epidemiological exposure) and liver biopsy can elucidate the diagnosis.
\end{abstract}

Keywords: Visceral leishmaniasis, Liver failure, Leishmania, Leishmania infantum

\section{Background}

Leishmaniasis is an emerging infectious disease, caused by protozoa that live inside macrophages in mammals. Sandflies become infected after feeding on the reservoir animal (rodents, dogs, and other small mammals) or infected humans and can then transmit the parasite to other humans [1].

Clinical manifestations are dependent both on the infecting species of Leishmania and the immune response of the host. Many cases are asymptomatic, reflecting the ability of the host immune system to control the parasite. There are two main clinical forms: visceral leishmaniasis

\footnotetext{
* Correspondence: jambrosioni@intramed.net

${ }^{2}$ Infectious Diseases Service Hospital Clinic-IDIBAPS, Villarroel 170, 08032

Barcelona, Spain

Full list of author information is available at the end of the article
}

and cutaneous leishmaniasis. Cutaneous leishmaniasis presents as single or multiple papular, nodular or ulcerous skin lesions. Visceral leishmaniasis is the most serious clinical form of this disease. Persistent fever, splenomegaly and pancytopenia characterize visceral leishmaniasis [1]. An infrequent form of leishmaniasis is localized leishmanial lymphadenopathy without fever or skin lesions. After the largest outbreak of leishmaniasis in Europe a series of cases of localized leishmanial lymphadenopathy was published. The presentation as fulminant hepatitis is even more uncommon [2].

The global incidence of visceral leishmaniasis decreased substantially in the past decade: from between 200,000 and 400,000 new cases in 2012, to between 50, 000 and 90,000 new cases in 2017 [1]. Among tropical diseases, leishmaniasis ranks second in mortality and

(c) The Author(s). 2019 Open Access This article is distributed under the terms of the Creative Commons Attribution 4.0 International License (http://creativecommons.org/licenses/by/4.0/), which permits unrestricted use, distribution, and reproduction in any medium, provided you give appropriate credit to the original author(s) and the source, provide a link to the Creative Commons license, and indicate if changes were made. The Creative Commons Public Domain Dedication waiver (http://creativecommons.org/publicdomain/zero/1.0/) applies to the data made available in this article, unless otherwise stated. 
seventh in loss of disability-adjusted life years [3]. Outbreaks of human leishmaniasis are unusual in Spain, despite being considered an endemic disease. Here we describe a case of acute hepatitis with liver failure as visceral leishmaniasis presentation in an immunocompetent adult from an urban area in Barcelona.

\section{Case presentation}

A 55-year-old man resident in Barcelona was evaluated for a 2-week history of unexplained fever despite antipyretic treatment. Medical record was positive only for hypertension controlled with enalapril. $\mathrm{He}$ was born in Barcelona and he always lived there. 2 years ago he had traveled to China and Israel, and 10 years ago to several countries of South America, with no other relevant epidemiological risk. The patient denied alcohol intake previous to admission At admission he was $39.1{ }^{\circ} \mathrm{C}$, the heart rate was $89 \mathrm{bpm}$, and the blood pressure was $123 / 66 \mathrm{mmHg}$. Physical examination was unremarkable. Initial blood test revealed increased C-reactive protein levels to $10.55 \mathrm{mg} /$ $\mathrm{dL}$, elevated aspartate aminotransferase $(88 \mathrm{U} / \mathrm{L})$, alanine aminotransferase $(76 \mathrm{U} / \mathrm{L})$, alkaline phosphatase $(202 \mathrm{U} / \mathrm{L})$ and gamma glutamyl transferase (269 U/L). Bilirubin and prothrombin time were within normal range. The hemoglobin was $12.7 \mathrm{~g} / \mathrm{dl}$ and laboratory test showed leukopenia $\left(2.83 \times 10^{9} / \mathrm{L}\right)$ and thrombopenia $\left(115 \times 10^{9}\right)$. Blood and urine cultures were taken on admission. Chest radiography was normal. Due to fever and analytical results it was decided to perform an abdominal ultrasonography revealing a hypoechoic lesion suggestive of a subcapsular splenic infarction. Infective endocarditis was suspected, starting an antibiotic combination of intravenous ampicillin $2 \mathrm{~g} / 4 \mathrm{hs}$, cloxacillin $2 \mathrm{~g} / 4$ hs and ceftriaxone $2 \mathrm{~g} / 12$ hs. Transthoracic echocardiography was unremarkable and blood cultures were negative, discontinuing ampicillin and cloxacillin.

The patient continued having febrile peaks over 2 weeks, treated mainly by physical measures to avoid hepatotoxic drugs. A computed tomography revealed 15 $\mathrm{cm}$-splenomegaly and several splenic infarctions, with no other abnormalities. Repeated blood analysis showed worsening of liver tests (AST $1649 \mathrm{U} / \mathrm{L}$, ALT $911 \mathrm{U} / \mathrm{L}$, gamma GT $447 \mathrm{U} / \mathrm{L}$, total bilirubin $4.20 \mathrm{mg} / \mathrm{dl}$, ammonium $82 \mu \mathrm{mol} / \mathrm{L}$, albumin $2.4 \mathrm{mg} / \mathrm{dl}$, prothrombin time of $40 \%$ ), pancytopenia (hemoglobin $8 \mathrm{~g} / \mathrm{L}$, platelets $48 \times 10^{9}$ ), high levels of triglycerides $222 \mathrm{mg} / \mathrm{dl}$, elevated ferritin $12.886 \mathrm{ng} / \mathrm{mL}$, lactic dehydrogenase 915 $\mathrm{U} / \mathrm{L}$, total proteins $55 \mathrm{~g} / \mathrm{l}$, normal kidney function test and normal blood smear.

Microbiology investigations (including serologies and molecular biology) were negative for tuberculosis, Coxiella, Brucella, Human immunodeficiency virus, viral hepatitis (A to E), Cytomegalovirus, Epstein-Barr virus and parvovirus B19. IgG for Leishmania was positive, with a title of 1:200 by IIFT technique and IgM was negative. He had low titers of antinuclear and anti-smooth muscle antibodies (1:80). Given these findings it was decided to perform a bone marrow aspiration and a ${ }^{18} \mathrm{~F}$-fluorodeoxyglucose-positron emission tomography in combination with computed tomography scanning (FDG$\mathrm{PET} / \mathrm{TC}$ ). There were no signs of haematologic malignancy in the bone marrow and there were no hemophagocytosis. Aspirated material inoculated into parasitic growth media and a Giemsa-stained smear was made, both were negative. FDG-PET/TC revealed a diffuse high uptake in the spleen, liver, and bone marrow but without involvement of lymph nodes or other organs (Fig. 1).

Given the worsening of liver tests, a diagnostic liver biopsy was performed and histopathology showed an acute hepatitis with confluent necrosis and mixed inflammatory infiltrates with abundant plasmatic and histiocytic cells. Isolated macrophages with intracytoplasmic Leishmania amastigotes were observed (Fig. 2). Polymerase chain reaction in tissue was positive for Leishmania infantum. The patient started treatment with liposomal amphotericin B $3 \mathrm{mg} / \mathrm{kg} /$ day for 5 days and two additional single weekly doses, at day 14th and 21st, showing slow but continuous analytical and clinical involvement. He was completely recovered 1 month later.

\section{Discussion and conclusion}

In 2017 the global incidence of visceral leishmaniasis was 50.000-90.000 new cases. Persistent irregular fever, splenomegaly, pancytopenia, weight loss and hypergammaglobulinemia characterize visceral leishmaniasis. Hepatomegaly is common in patients with

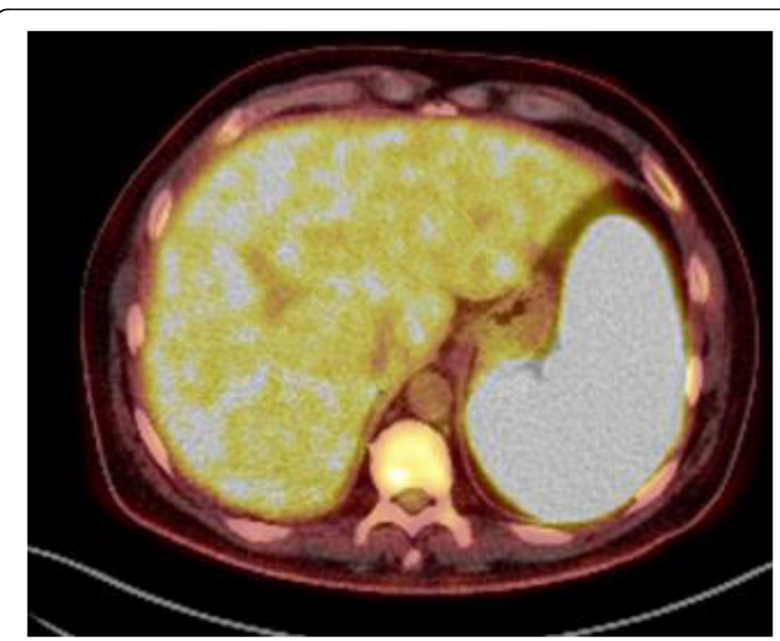

Fig. 1 FDG-PET/TC. FDG-PET scans shows diffuse high uptake in the spleen (SUV máx: 13.26), liver, and bone marrow 


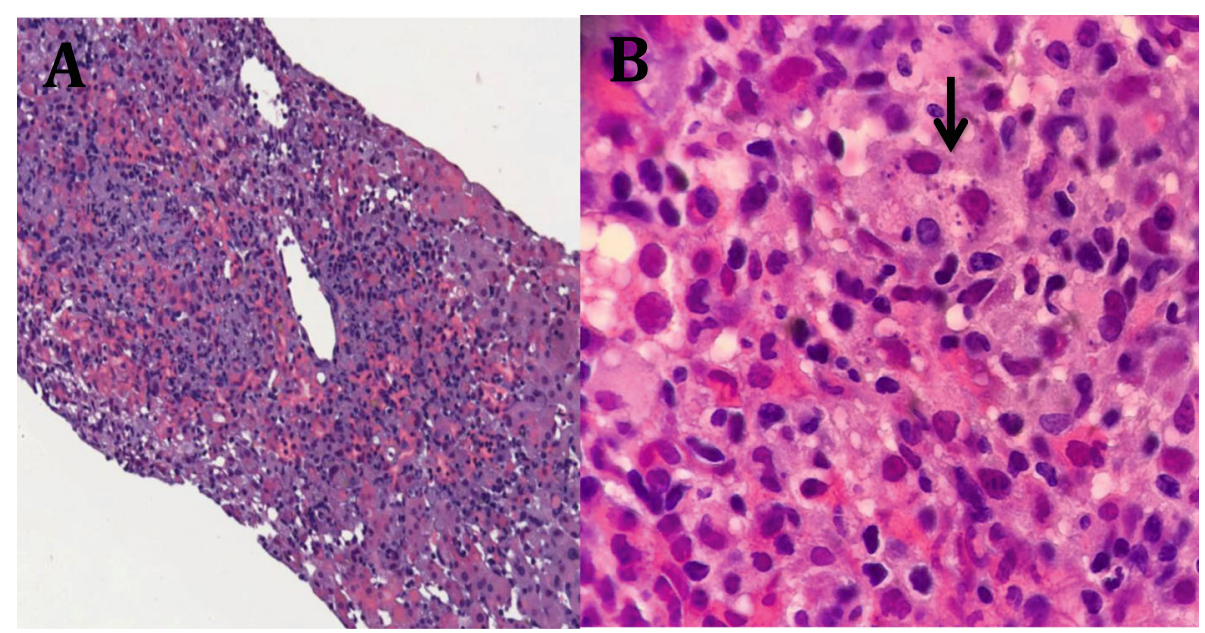

Fig. 2 Histopathological study of the liver. a On the left side, liver biopsy showed an acute hepatitis with centrilobular necrosis, mixed inflammation and abundant Kupffer cells (Hematoxilin \& Eosin, 10X). b Scattered small oval structures with rod-shaped kinetoplast (black arrow) were observed in the cytoplasm of some hepatocytes and Kupffer cells (Hematoxilin \& Eosin, 40X)

visceral leishmaniasis and late in the course of disease, hepatic dysfunction, jaundice, and ascites can occur [1]. However rapid acute progressive hepatitis as a presenting feature is rare.

Definitive diagnosis of visceral leishmaniasis requires demonstration of the parasite by either histopathology or culture of material obtained by needle aspiration or biopsy from affected organs (usually bone marrow or spleen). In our case we performed a bone marrow aspiration and aspirated material inoculated into parasitic growth media and a Giemsastained smear was made, but both were negative. Unfortunately, PCR was not available in our institution, what may have provided an earlier diagnosis. Death occurs in more than $90 \%$ of patients without specific anti-leishmanial treatment. Therefore, a correct diagnosis of visceral leishmaniasis is essential. After obtaining negative results from the bone marrow aspirate, we performed a liver biopsy. Intracytoplasmic Leishmania amastigotes were observed in the liver biopsy specimens and a polymerase chain reaction requested to the national reference center confirmed the diagnosis.

Only few cases of acute hepatitis as a presenting form of visceral leishmaniasis are reported in the literature and many of them do not have a histopathological study of the liver. Just 4 previous cases with a liver biopsy were reported so far. The cases are summarized in the table (Table 1) [4-7]. Three of the published cases are in children, in Indian [7]. Since visceral leishmaniasis preferentially affects children or immunosuppressed adults, interestingly, in this adult patient, no evidenced of immunodeficiency was detected.
The liver involvement in visceral leishmaniasis may appear as chronic granulomatous hepatitis [8]. El $\mathrm{Hag}$ et al has reported histopathology changes in the liver in visceral leishmaniasis [9]. All cases had inflammation, Kupffer cell hyperplasia, intracellular amastigotes, focal and piecemeal necrosis. The histopathological findings of the case reported here mimics that published last year by Bassegoda et al. (also from Barcelona) and evidenced diffuse hepatitis process, a necro-inflammatory pattern, accompanying inflammatory infiltrate was mixed, with abundant plasmatic and histiocytic cells, without forming granulomas [6]. Very small, oval structures in the cytoplasm of some macrophages were suggestive of Leishmania amastigotes. The disease is rare in Spain and no common exposure or link could be traced between the two cases. Although a clear epidemiological exposure for our case was not identified, Leishmania infantum is endemic in the Mediterranean basin and therefore, exposure could have occurred even in Spain [1]. Interestingly the two only adult cases were from Barcelona and both had negative Leishmania detection in bone marrow samples.

Acute hepatitis is an uncommon debut of visceral leishmaniasis in immunocompetent patients. Furthermore there are only few cases in the literature that describe the histopathological changes that we found in this patient. In conclusion, in case of acute hepatitis leading to liver failure, leishmaniasis should be considered a differential diagnosis (even in non-endemic countries and without clear epidemiological exposure) and liver biopsy can elucidate the diagnosis. 


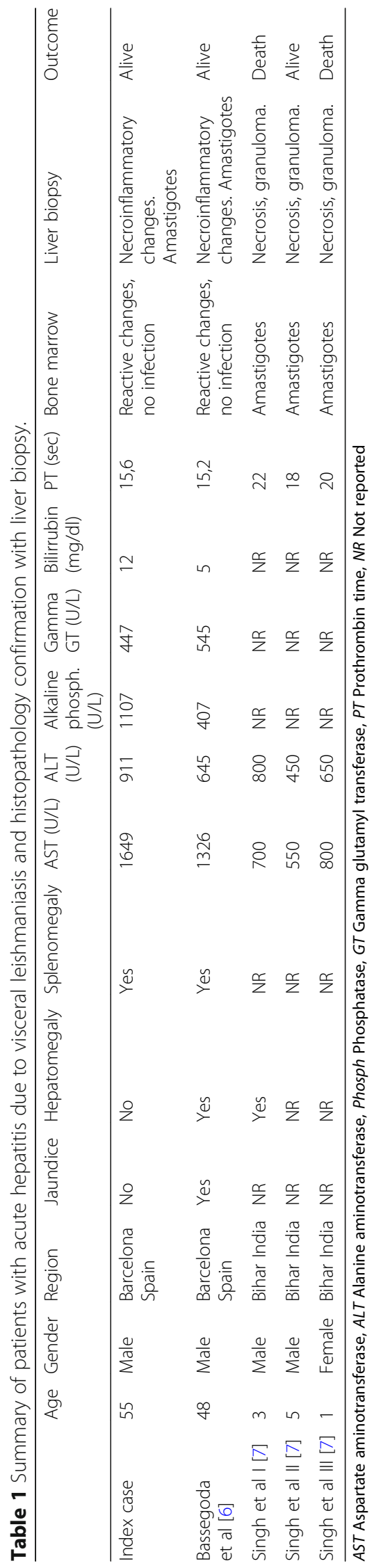




\section{Abbreviations}

ALT: Alanine aminotransferase; AST: Aspartate aminotransferase; FDG-PET/ TC: ${ }^{18}$ F-fluorodeoxyglucose-positron emission tomography in combination with computed tomography scanning; GT: Gamma glutamyl transferase; NR: Not reported; Phosph: Phosphatase; PT: Prothrombin time

\section{Acknowledgments}

We thank the patient for consenting to publication of his clinical data.

\section{Authors' contributions}

$I M$ and JA drafted the manuscript. AD, OB, AC, CF, MEV, MJA, CG, AS and JAM revised it critically for important intellectual content. All authors read and approved the final manuscript.

\section{Funding}

No funding was obtained for this study.

\section{Availability of data and materials}

Data sharing is not applicable to this article as no datasets were generated or analyzed during the current study. The corresponding author Juan Ambrosioni should be contacted.

\section{Ethics approval and consent to participate}

Not applicable.

\section{Consent for publication}

Written informed consent was obtained from the patient for publication of this case report and other accompanying images. This consent form is available on request.

\section{Competing interests}

The authors declare that they have no competing interests.

\section{Author details}

${ }^{1}$ Internal Medicine Service, Hospital San Pedro, Logroño, Spain. ${ }^{2}$ Infectious Diseases Service Hospital Clinic-IDIBAPS, Villarroel 170, 08032 Barcelona, Spain. ${ }^{3}$ Pathology Service, Hospital Clinic-IDIBAPS, Barcelona, Spain.

${ }^{4}$ Hepathology Service, Hospital Clinic-IDIBAPS, Barcelona, Spain.

${ }^{5}$ Microbiology Dpt-CDB, Hospital Clinic-ISGLOBAL, Barcelona, Spain.

Received: 16 June 2019 Accepted: 3 October 2019

Published online: 22 October 2019

\section{References}

1. Burza S, Croft SL, Boelaert M. Leishmaniasis. Lancet. 2018;392(10151):951-70.

2. Horrillo L, San Martín JV, Molina L, Madroñal E, Matía B, Castro A, et al. Atypical presentation in adults in the largest community outbreak of leishmaniasis in Europe (Fuenlabra, Spain). Clin Microbiol Infect. 2015;21(3): 269-73.

3. Wang H, Naghavi M, Allen C, Barber RM, Bhutta ZA, Carter A, et al. Global, regional, and national life expectancy, all-cause mortality, and cause-specific mortality for 249 causes of death, 1980-2015: a systematic analysis for the global burden of disease study 2015. Lancet. 2016;388(10053):1459.

4. Girbau A, Baliellas C, Castellote J, de la Banda E. Acute hepatitis and fever. Enferm Infecc Microbiol Clin. 2010;28(8):556-7.

5. Sagnelli C, Di Martino F, Coppola N, Crisci A, Sagnelli E. Acute liver failure: a rare clinical presentation of visceral leishmaniasis. New Microbiol. 2012;35(1):93-5.

6. Bassegoda O, Solé C, Diaz A. An unusual cause of acute severe hepatitis. Gastroenterology. 2019;156(1):e3-4. https:/doi.org/10.1053/.gastro.2018.08.046.

7. Baranwal AK, Mandal RN, Singh R. Fulminant hepatic failure complicating visceral leishmaniasis in an apparently immunocompetent child. Indian J Pediatr. 2007;74(5):489-91.

8. Khanlari B, Bodmer M, Terracciano L, Heim MH, Fluckiger U, Weisser M. Hepatitis with fibrin-ring granulomas. Infection. 2008;36(4):381-3.

9. El Hag IA, Hashim FA, el Toum IA, Homeida M, el Kalifa M, el Hassan AM. Liver morphology and function in visceral leishmaniasis (Kala-azar). J Clin Pathol. 1994;47(6):547-51.

\section{Publisher's Note}

Springer Nature remains neutral with regard to jurisdictional claims in published maps and institutional affiliations.

\section{Ready to submit your research? Choose BMC and benefit from:}

- fast, convenient online submission

- thorough peer review by experienced researchers in your field

- rapid publication on acceptance

- support for research data, including large and complex data types

- gold Open Access which fosters wider collaboration and increased citations

- maximum visibility for your research: over $100 \mathrm{M}$ website views per year

At BMC, research is always in progress.

Learn more biomedcentral.com/submissions 